\title{
Regulação Emocional em Psicoterapia: um guia para o terapeuta cognitivo-comportamental
}

\author{
Robert L. Leaby, Dennis Tirch \& Lisa A. Napolitano (2013). Trad. Ivo Oliveira. Porto Alegre: Artmed. 331 p.
}

Este texto apresenta o livro Regulação Emocional em Psicoterapia: um guia para o terapeuta cognitivo-comportamental, que se trata de uma importante e bastante atualizada publicação, voltada para terapeutas da psicoterapia cognitivo-comportamental contemporânea. O livro é demasiadamente rico em detalhes práticos e ele aborda os temas a partir de um arcabouço teórico bastante consistente e de fácil compreensão. Estas são características das obras do autor Robert Leahy, sendo ele considerado uma referência entre profissionais e estudantes da abordagem cognitivo-comportamental.

O livro é composto por 331 páginas, estando dividido em 11 capítulos. É possível entender a obra, a partir de três partes fundamentais. A primeira parte visa apresentar o conceito de emoção e discutir a importância da regulação emocional nos processos psicoterapêuticos, sendo composta exclusivamente pelo primeiro capítulo. Já a segunda parte compõe-se pelos 10 capítulos seguintes, os quais versam a respeito de técnicas/práticas para a regulação emocional, finalizando com um capítulo mais geral, de conclusão. Por fim, a terceira parte é formada por uma ampla gama de formulários e atividades para reprodução e utilização no cotidiano da clínica, disponibilizados no apêndice do livro. Neste texto, optou-se por dar maior foco às duas primeiras partes, em função de o seu conteúdo ser mais genérico, sendo a terceira parte, relativamente "aplicada", não sendo, por isso, alvo de maiores detalhes neste texto.

Como uma breve apresentação do "esqueleto" do livro, o capítulo 1 é intitulado "Por que a regulação emocional é importante?", seguido do capítulo chamado "Terapia do esquema emocional". O capítulo seguinte foi intitulado "Validação", seguido do capítulo quatro, denominado "Identificação e refutação de mitos emocionais"; o capítulo cinco, "Atenção Plena (Mindfulness)"; o capítulo seis, "Aceitação e disposição"; e o capítulo sete "Treinamento da mente compassiva". Além desses, ainda há o capítulo número oito, o qual foi denominado "Como melhorar o processamento das emoções", o capítulo nove, "Reestruturação cognitiva"; e, por fim, o capítulo intitulado "Redução do estresse".

A respeito do capítulo 1, o qual foi intitulado "Por que a regulação emocional é importante", percebe-se que o mesmo constrói uma discussão a respeito do conceito, das funções e da regulação das emoções, e, além disso, acerca da importância e implicação da regulação emocional nos processos psicoterapêuticos baseados em TCC (terapia cognitivo-comportamental). Neste capítulo, as emoções são consideradas um conjunto de processos multidimensionais e "indissociáveis", sendo estes "requisitos" para a sua constatação. Adicionalmente, as emoções são citadas com a função de ajudar a avaliar as alternativas possíveis, oferecendo a motivação para a apresentação de um comportamento (fazer algo).

As emoções se consolidam como uma representação mais abrangente na experiência humana, conforme exemplificam os autores:

\begin{abstract}
Ao ter a emoção "ansiedade", reconbece-se que há uma preocupação, baseada em uma avaliação (ex. não conseguirá ou de que não dará certo), associado a isso, o ritmo cardíaco acelera (sensação), então o sujeito concentra-se na competência (intencionalidade), tem sentimentos em relação à vida (sentimento), $e$ dessa forma, acaba tornando-se agitado (comportamento motor), e pode, quem sabe ainda, dizer a alguém que está em um dia ruim (interpessoal) (p.19).
\end{abstract}

Para os autores, as emoções revelam de alguma forma, as necessidades humanas, e ainda neste primeiro capítulo são apresentados os aspectos neurobiológicos envolvidos nas emoções, os quais estão descritos pelos dos modelos "descendente" e "ascendente".

Neste capítulo faz-se um resgate teórico sobre a evolução da "curiosidade", da importância e do conceito das emoções ao longo da história. Este resgate tem início em Platão, na Filosofia Ocidental, perpassando os filósofos estoicos, influenciando, mais tarde, os trabalhos de Darwin, tornando-se alvo de investigação até os dias de hoje. Na sequência, o livro se direciona para as estratégias em lidar com as emoções, apresentando algumas delas e introduzindo o conceito de regulação. Regulação emocional é definida como uma estratégia de enfrentamento, podendo sê-la, de duas formas: problemática ou adaptativa.

Segundo os autores, saber lidar com as emoções de maneira adaptativa pode levar a redução da intensidade das mesmas e da sua exacerbação. São exemplos de estratégias adaptativas: os exercícios de relaxamento, os exercícios físicos, a distração temporária, a conexão entre as emoções e valores mais abrangentes, manipulação das emoções (substituição das emoções), mindfulness, 
aceitação, entre diversas outras. Ainda neste capítulo, os autores sugerem que a regulação das emoções desempenha importante papel em vários transtornos, dentre eles o TAG (transtorno de ansiedade generalizada), o TPB (transtorno de personalidade borderline), além dos de ordem alimentar. Para a finalização deste capítulo, há uma discussão sobre a causalidade entre "razão e emoção", não havendo, segundo os autores, primazia entre os termos.

O segundo capítulo apresenta a TEE (terapia do esquema emocional), abordagem cuja epistemologia se baseia em autores como Beck e Young. $\mathrm{O}$ enfoque central dessa abordagem está nos esquemas de associação entre as emoções e as áreas da vida do indivíduo, bem como nas estratégias individuais para lidar com elas. Os esquemas emocionais são descritos como "filosofias individuais" que se têm a respeito das emoções. Considerando este cenário no contexto terapêutico, identificam- se as emoções e as estratégias esquematizadas para lidar com elas. Neste capítulo também estão descritas as seguintes técnicas: identificação das emoções, rotulação das emoções, normalização de emoções, percepção da temporalidade das emoções, além da técnica de exploração das emoções como meta, dentre outras. São sugeridas, também, questões a serem propostas durante a intervenção com os clientes, exemplos clínicos práticos, tarefas de casa e a designação de formulários específicos, estando exclusivamente estes últimos no apêndice do livro (em torno de 80 sugestões).

O capítulo seguinte é chamado de "Validação" e aborda, de início, a teoria do apego de Bowlby, sendo, para os autores, associada com a forma como se deu a validação dos sentimentos por parte dos adultos, a partir da comunicação das emoções feita pelas crianças. Validar as emoções está relacionado com percebê-las e aceitá-las e, por isso, está associado com questões como empatia e olhar positivo incondicional, tanto por parte do terapeuta com seu cliente (Rogers), como do cliente com suas próprias vivências e emoções. Neste capítulo ainda são apresentadas as seguintes técnicas: resistência à validação, exame do significado da invalidação, desenvolvimento de estratégias para lidar com a invalidação, dentre outras. Adicionalmente são propostas questões para serem operacionalizadas durante as sessões terapêuticas, bem como exemplos clínicos práticos e a designação de formulários específicos, referentes a isso.

No quarto capítulo, intitulado "Identificação e refutação de mitos emocionais", são apresentados alguns conceitos da TCD (terapia comportamental dialética). Nessa abordagem busca-se delimitar as crenças equivocadas referentes às emoções, descritas nesta abordagem como os "mitos emocionais". Nesse modelo há certo incentivo no desafio às crenças referentes às emoções e é voltado para o TPB (transtorno de personalidade borderline). Como técnicas para tal, são apresentadas: identificação dos mitos emocionais, apresentação de uma teoria sobre as emoções para o cliente, a identificação da origem dos mitos emocionais, dentre outras. No capitulo são apresentados, da mesma forma que nos demais, questões a serem propostas durante as intervenções, tarefas de casa, exemplos clínicos e as sugestões dos formulários contidos no apêndice do livro.

O quinto capítulo trata das práticas de mindfulnes (atenção plena) como uma das formas para alcançar autorregulação emocional, em razão de a mesma levar o praticante a um distanciamento de "si próprio", a fim de permitir a observação das emoções sem julgamento, para, então, a aplicação de técnicas para sua autorregulação, tais como o escaneamento corporal, a atenção sobre a respiração, a aceitação consciente, dentre outras. Neste capítulo os autores ainda fazem um breve resgate bibliográfico referente às primeiras aplicações das práticas em psicoterapia, bem como apresentam algumas discussões acerca de sua epistemologia, associada à cultura oriental. Além disso, exemplos clínicos envolvendo as práticas de atenção plena, questões a serem abordadas com o cliente durante as intervenções e algumas tarefas de casa, são apresentados.

Com intuito de desenvolver aceitação no cliente, este capítulo se associa aos dois seguintes, designados "Aceitação e disposição" e "Treinamento da mente compassiva", no qual são apresentados técnicas e fundamentos da ACT (terapia da aceitação e compromisso/comprometimento), dentre os quais a técnica da desfusão cognitiva e o uso de metáforas. Adicionalmente, apresenta-se a TFC (terapia focada na compaixão), a qual busca o desenvolvimento da "compaixão", sendo esta definida como um facilitador do processo de autorregulação. Os autores também fazem uma pequena discussão com relação aos termos mindfulness e meditação.

Já no capítulo oito, chamado "Como melhorar o processamento das informações", são discutidas algumas técnicas e fundamentos da TFE (terapia focada nas emoções), a qual se volta para a aliança psicoterápica como "regulador" das emoções, de forma que esse vínculo possa ser generalizado para a vida cotidiana dos clientes. Complementarmente, o capítulo nove volta-se 
para a TCC (terapia cognitivo comportamental), mas especificamente sobre o processo de reestruturação cognitiva, cujo objetivo é modificar as interpretações que são dadas aos eventos para, com isso, haver uma redução no impacto das emoções. Nestes dois capítulos também são descritas algumas técnicas, tarefas de casa, além de alguns exemplos clínicos práticos, questões a serem abordadas durante as intervenções terapêuticas e, por fim, a indicação de formulários.

Denominado "Redução do estresse", o décimo capítulo inicia discutindo o conceito de estresse, referindo-se a um estado de alarme, através da ativação do eixo hipotalâmico-hipofisário-suprarrenal (HHSR), estando o fenômeno associado com os processos de regulação emocional e com a adaptação do indivíduo, de uma forma geral. Incorporado a esse funcionamento de ativação do estresse estão os processos implícitos de avaliação cognitiva. Ainda neste capitulo, o relaxamento é descrito como um competidor, dentro do organismo, das reações do estresse, uma vez que "transporta" o organismo do sistema nervoso simpático (associado ao estresse) para o parassimpático (associado ao relaxamento). Por fim, são apresentadas algumas técnicas, como a respiração diafragmática, o relaxamento muscular progressivo, as imagens mentais positivas, dentre outras, e, adicionalmente, são disponibilizados exemplos clínicos práticos, questões propostas para as intervenções e os formulários específicos para essa demanda.

Concluída a apresentação do livro, faz-se significativo destacar que aqueles terapeutas que percebem a necessidade de utilizar técnicas para desenvolver a regulação emocional de seus clientes encontrarão neste guia uma rica fonte de informações. Além disso, cabe salientar que o livro cumpre o papel que se propõe, apresentando temáticas que se relacionam com a questão da regulação emocional em processos psicoterapêuticos, de maneira didática.

O livro discute os principais conceitos referentes à área, de maneira diversificada, apresentando referências atuais, excelente argumentação, além de exemplos clínicos bastante compreensíveis. Outro ponto positivo do livro é que ele apresenta uma extensa fonte de materiais para serem utilizados no dia a dia da clinica cognitivo-comportamental, ou mesmo das demais abordagens apresentadas no mesmo. Para finalizar este texto, reitera-se que qualquer profissional, independente do nível e do tempo de capacitação e mesmo da experiência enquanto psicoterapeuta, poderá se beneficiar com este material.

Sobre o autor:

Jeferson Pires é psicólogo e aluno do Programa de Pós-Graduação em Psicologia da Universidade Federal de Santa Catarina, na linha de avaliação em saúde e desenvolvimento, em nível de mestrado. Atualmente integra o Laboratório de Pesquisa em Avaliação Psicológica e o Laboratório de Educação Cerebral, ambos na UFSC.

\section{Contato com o autor:}

Universidade Federal de Santa Catarina

Centro de Filosofia e Ciências Humanas, Departamento de Psicologia

Trindade - 88040-970 - Florianopolis, SC - Brasil

E-mail: jefersongp@gmail.com 
